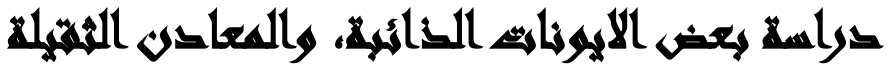

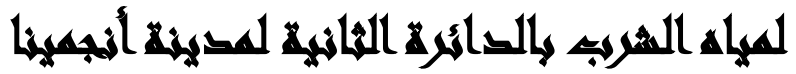

قمر محمد قمر (')- أحمد محمد مهاجر (r)

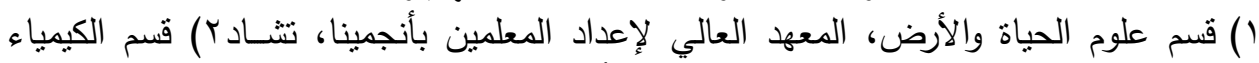

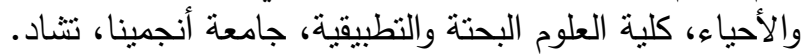

\section{المستخلم:}

جمعت عينات المياه قبل المعالجة (من البئر الارتوازي) وبعد المعالجة (من شبكة توزيع

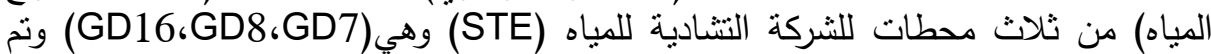

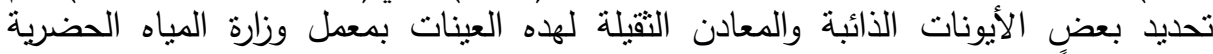

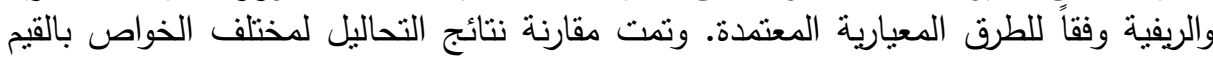

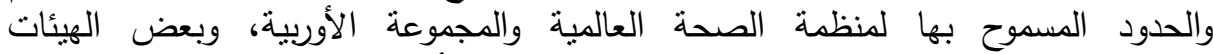

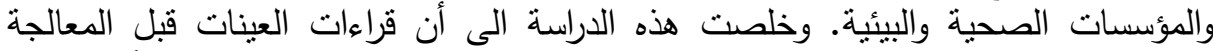

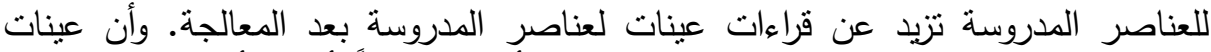

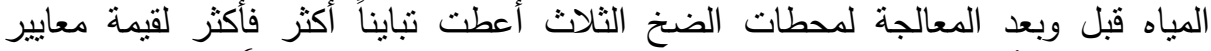

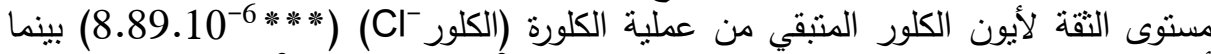

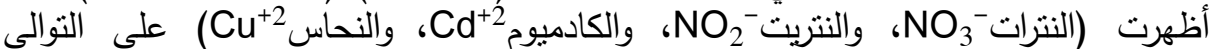

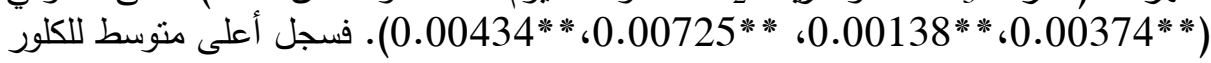

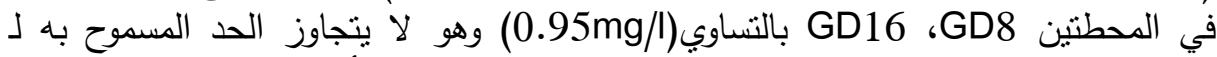

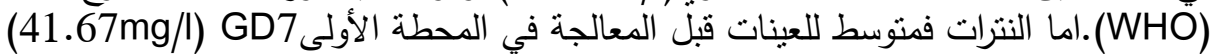

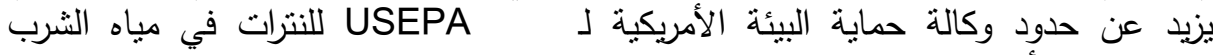

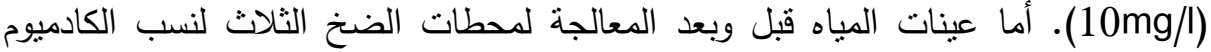

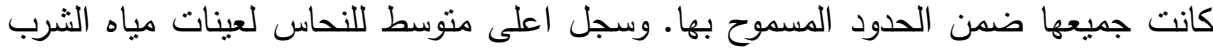
قبل المعالجة في المحطنين الثانية والثالثة (GD8،GD7) (2.12mg) وهو يتجاوز الحدود النيان

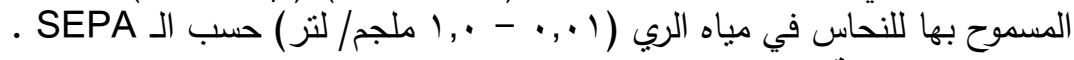
الكلمات المفتاحية Keywords: الايونات الذائبة، الكلور، النترات، النتريت، الكادميوم،

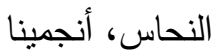

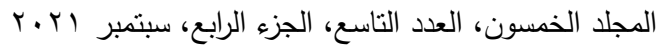

$$
\begin{aligned}
& \text { التزقيم الدولي 0826-1110 15SN } \\
& \text { الترقيم الدولي الموحد الإلكتروني 3178-2636 }
\end{aligned}
$$




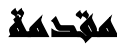

تعتبر المياه الصالحة للثرب من ضروريات حياة الكائنات الحية بما فيها الإنسان فيشكل الماء ما بربو عن الـ • \&\% من الغلاف الجوي، والماء هو أكثر المركبات انتشاراً في الطبيعة،

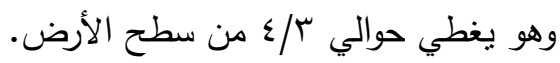
فالتلوث المائي الناجم عن سوء تخزين المياه في محطات ضخ التخ المياه أضحى يشكل

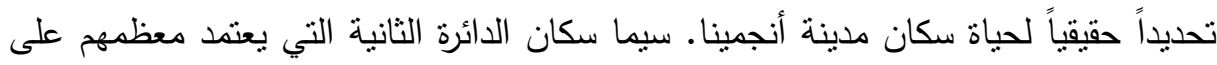
شبكات توزيع مياه الثركة النتادية للمياه. كما ينتج تلوث مياه الثركة عن عدم إنباع الصيانة

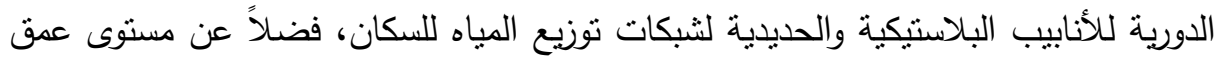

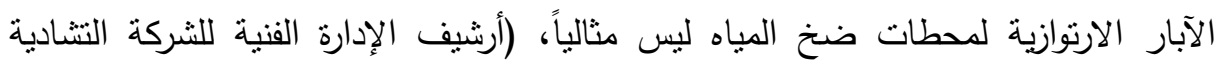

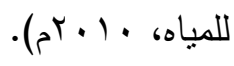
فحاجة الجسم للماء تعتمد على كمية فقدانه أثناء القيام بالأنشطة الحيوية المختلفة. في الحالة الطبيعية يحتاج الإنسان يوميا لحوالي (1 - r لتر) من الماء، وتحتاج كل عمليات

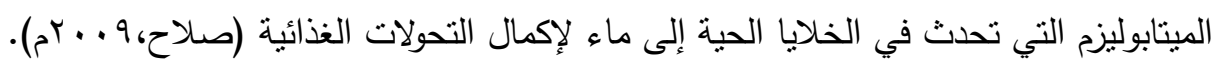
وتتراوح الأعراض التي تصيب الإنسان نتيجة استهلاكه لمياه ملوثة من الغنيان والنقيئ

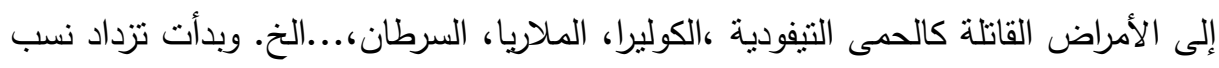
الإصابة بهذه الأمراض في المستشفيات نزامناً مع موسم هطول الأمطار .

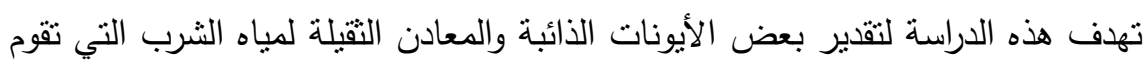
بتوزيعها الثركة التشادية للمياه (STE) لسكان مدينة أنجمينا وبالتحديد سكان الدائرة الثانية. ومقارنة نسب هذه المعايير بالحدود المسموح بها حسب مواصفات الهيئات الدولية المعنية

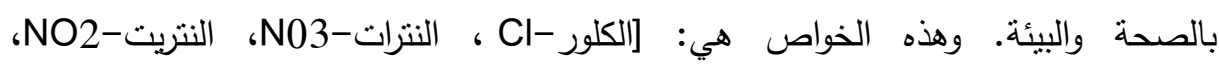

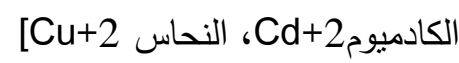

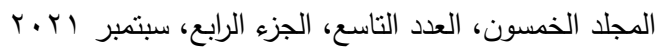

$$
\begin{aligned}
& \text { الترقيم الدولي 0826-1110 } \\
& \text { الترقيم الدولي الموحد الإكتروني 3178-2636 }
\end{aligned}
$$


1- الكلور الحر المتبقي Cl

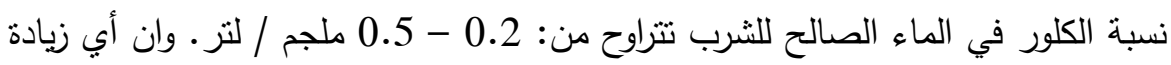
لتركيز الكلور عن هذه الحدود ستعرض الكائن الحي للعديد من المشاكل الصحية كالفنشل الكلوي، أمراض القلب، اضطرابات العظام، واضطرابات الجهاز الهضمي، نكلس العنان العظام

$$
\text { والأسنان ونقص في إنتاج حليب الأم ...الخ. }
$$

ولذلك يجب الأخذ في الاعتبار هذا الدذى لنسبة الكلور عند معالجة المباه الجوفية كما

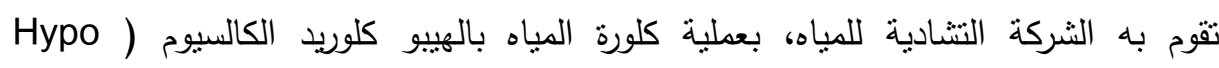

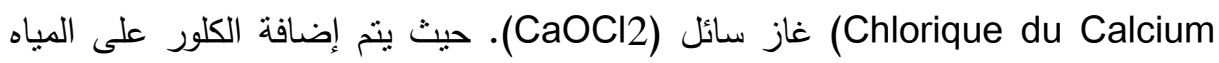

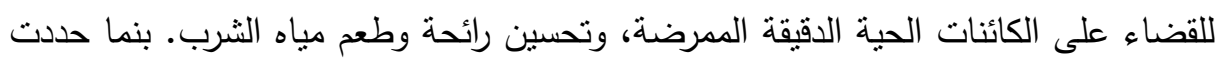

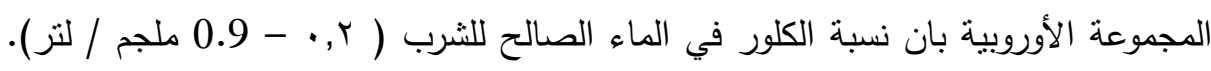

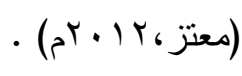

ويعتبر الكلور مطهراً ومبيداً. وأن تفاعله مع المواد العضوية النيتروجينية وغير العضوية

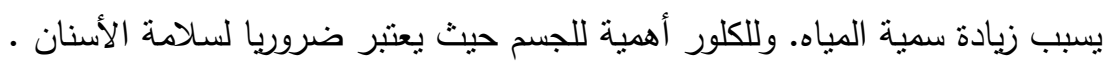
r - النترات

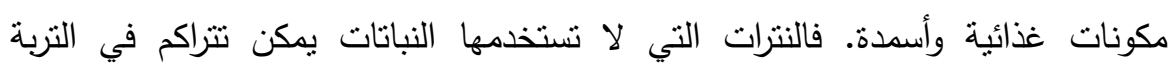

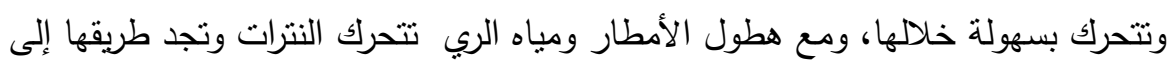

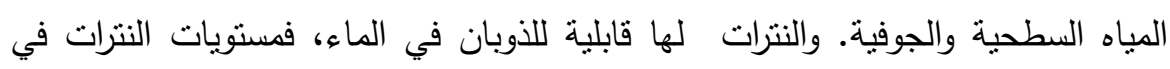

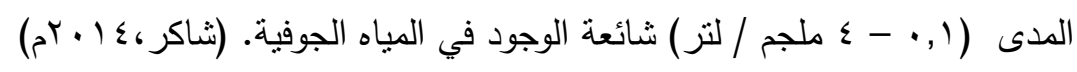

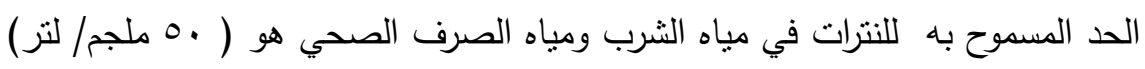
حسب منظمة الصحة العالمية (WHO,1993). بينما حددت وكالة فئلة حماية البيئة الأمريكية (USEPA,1997)

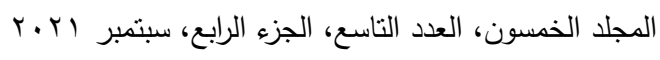

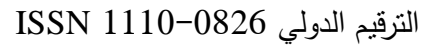

$$
\begin{aligned}
& \text { الترقيم الدولي الموحد الإلكتروني 3178-2636-26 }
\end{aligned}
$$


وأن الزيادة في نسبة النترات قد ترنبط بعدم وفرة الأوكسجين ومحتواه من المواد العضوية وهذا

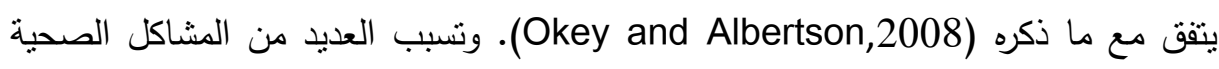
كنزيف في الطحال، إدرار البول، زيادة الترسبات النشوية، ومتلازمة الطفل الأزرق نتيجة

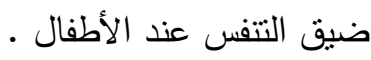

r- النتريت ${ }^{-}$ ملجم/ لتر) حسب وكالة حماية البيئة الصينية (SEPA,2005)، وكذلك حسب منظمة الصحة العالمية (WHO,1993). أهم مصادر التلوث بالنتريت تتمثل في استخدام

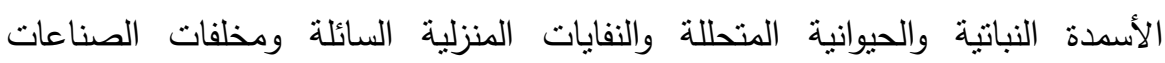
الكيميائية المختلفة في جميع مواقع أخذ العينات، وهذا بتفق مع ما ذكره ( السلمان

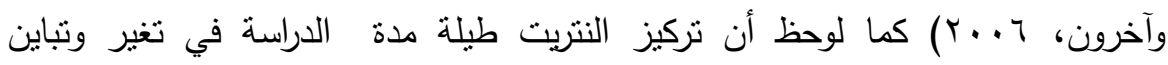
مستمرين في جميع المواقع. أملاح النتريت ذات مفعول سام، فهي تحل مكان الأوكسجين لتردين

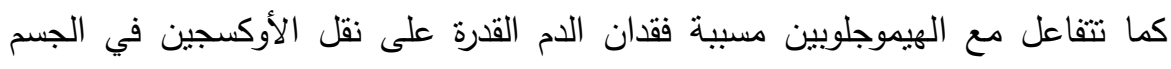
وبالتالي ضيق التتفس والوفاة ـ كما نتفاعل النتريت مع البروتينات في الجسم مكونا مادة

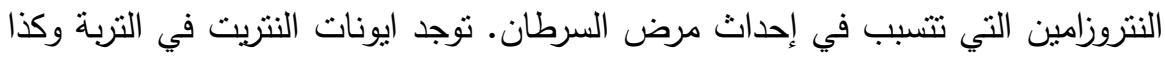

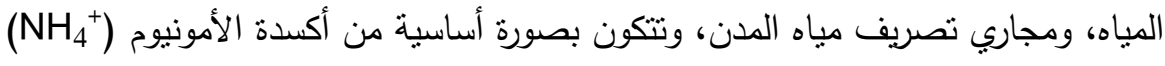
بواسطة بكتيريا النبتروباكتر، كما تتكون النتريت من خلال اختزال النترات في الهواء وبواسطة بكتيريا. وتحتوي المياه الناتجة من عمليات معالجة أسطح المعادن، وعمليات تتظيف غازات تحتوي على اكاسيد النيتروجين على نسبة مقدرة من النتريت. (مبروك، 
ع - الكادميوم Cadmium

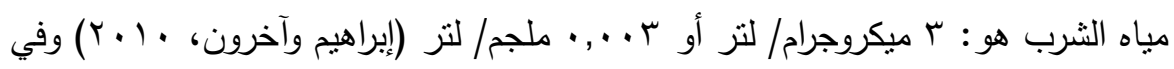
مياه الري (, • ملجم/ لتز ، حسب (FAO, 1992).

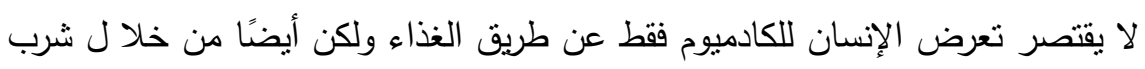

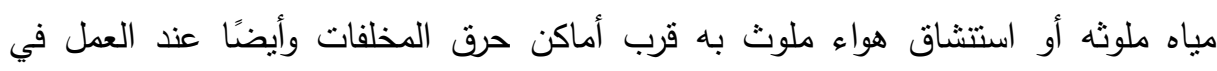

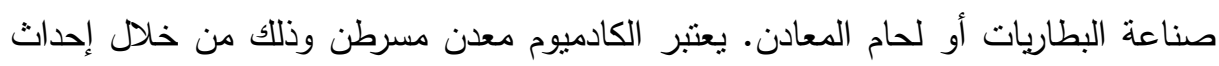

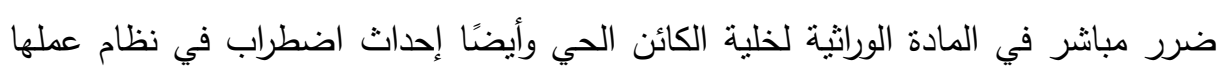

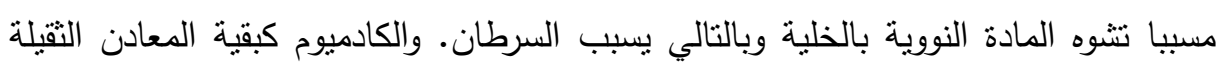

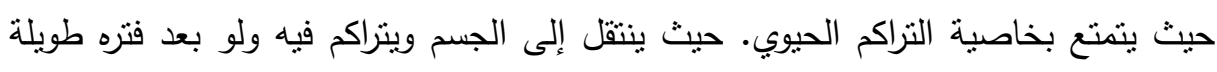

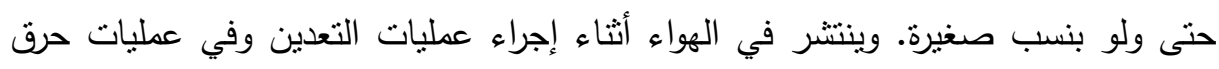

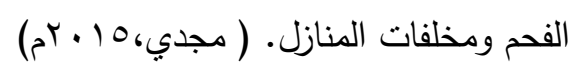

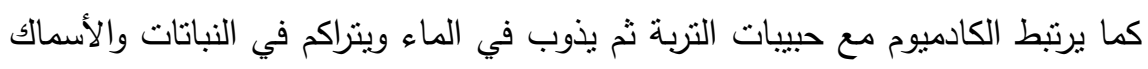

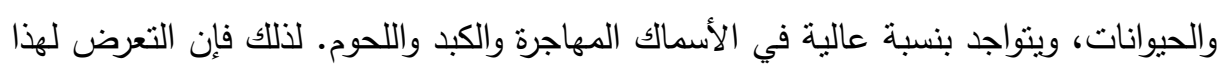

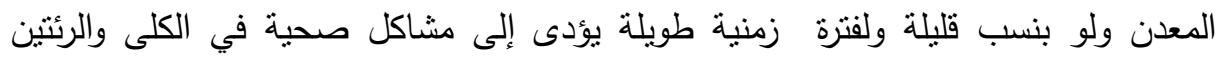
وهشاشة العظام وارتفاع ضغط الدم، إضافة لمشاكل في وظائف الكبد وتحطيم خلايا المخت.

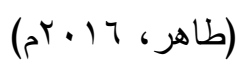

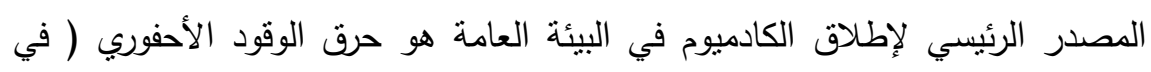

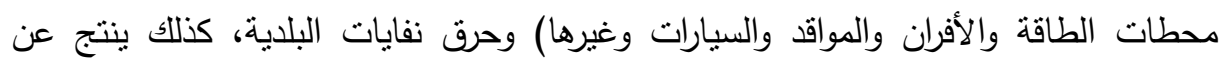

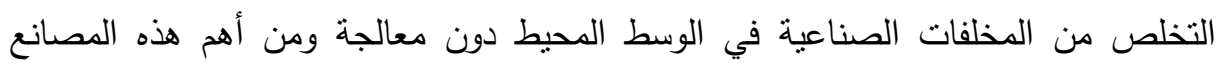

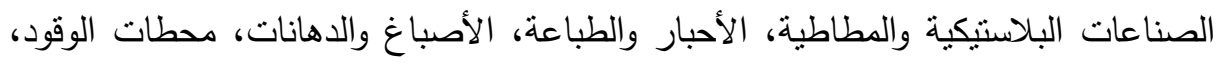

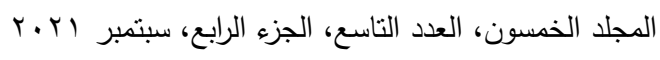

$$
\begin{aligned}
& \text { التزقيم الدولي 0826-0 الترني } \\
& \text { الترقيم الدولي الموحد الإلكتروني 3178-2636 }
\end{aligned}
$$


مصافي البترول، الصناعات الكهربائية والإلكترونية، مصانع الأسمدة وخاصة الأسمدة الفوسفاتية، صناعة البطاريات الجافة. ( طاهر، 7 ( • بrم) •-التحاس Cuver

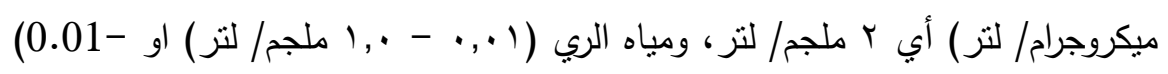

$$
\text { 1ppb) حسب الـ (USEPA,1997) }
$$

النحاس مادة لينة القوام قابلة للطرق، تتفاعل مع الجو مكونة نوع من الصدأ يعرف

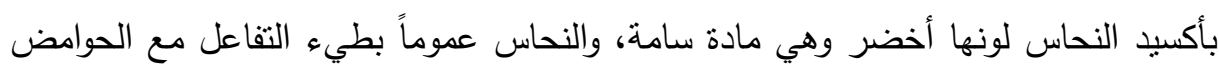

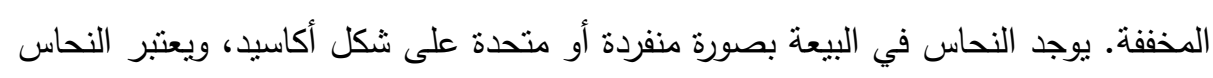
من أقدم المعادن التي اكتثفها الإنسان القديم. والنحاس مادة جيدة للتوصيل الحراري والتوصيل

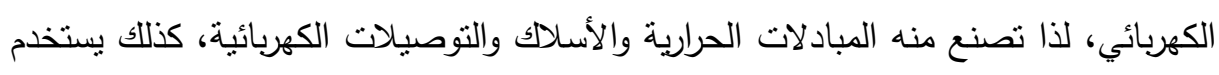

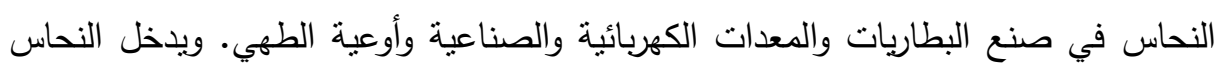

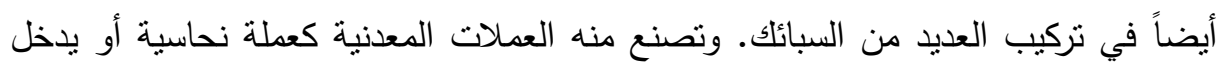

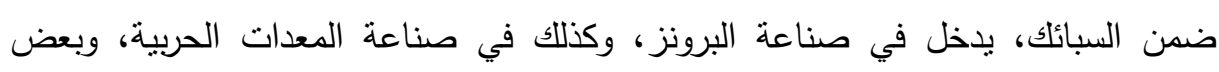

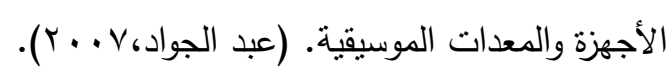

والنحاس عنصر قوي وجيد في تقوية العظام وجعلها أكثر صلابة ونقصه يؤدي إلى إنى

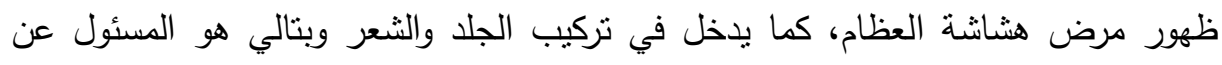

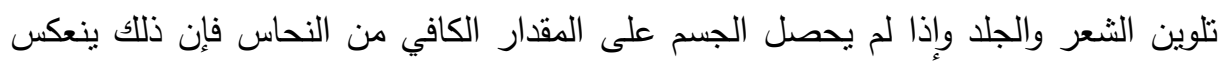

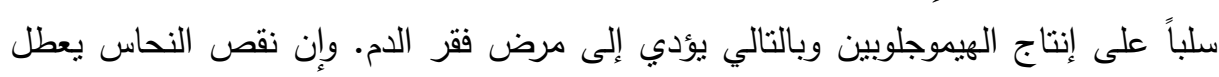

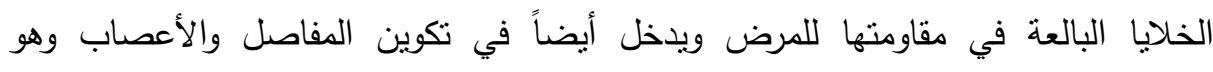

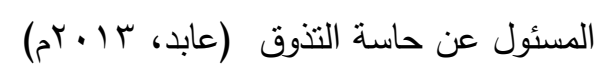

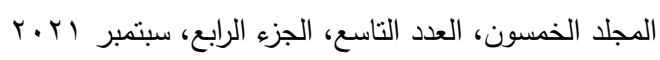

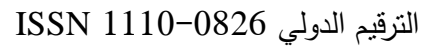

$$
\begin{aligned}
& \text { الترقيم الدولي الموحد الإلكتروني 3178-2636-26 }
\end{aligned}
$$




\section{الموات وطرة الهميثر}

ا. Study Site منطقة الدراسة

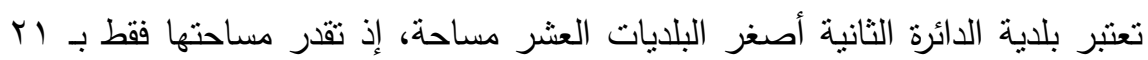

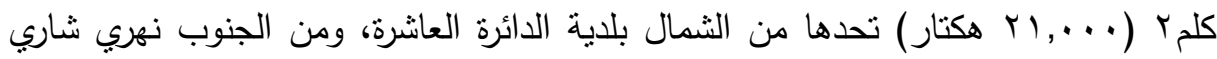

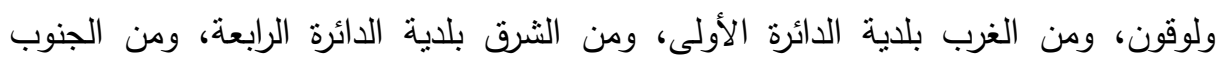

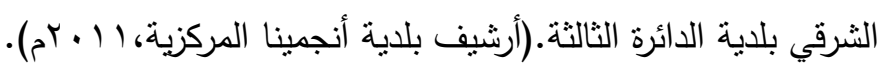

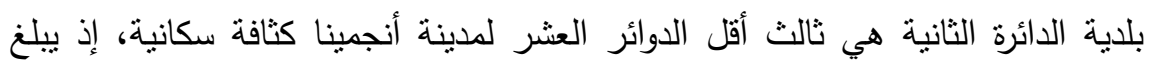

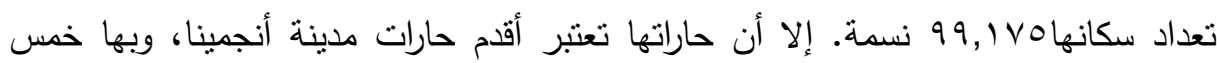
حارات ( بولولو، جمب القانو، قوجي، كليب مات، مرجان دفق، وجزء من شواطئ نهر شاري الذي يلتقي بنهر لوقون في خذ الدائرة) وتعتبر الدائرة الثانية هي المركز السياسي والإداري دوني

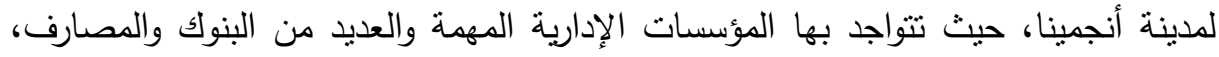
والمراكز التجارية والمستشفيات الكبيرة، والمؤسسات الحيوية، والساحات العامة.(أرشيف الأمانة

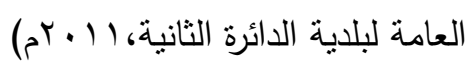
يوجد في الدائرة الثانية معظم خزانات وشبكات توزيع مباه الثرب للشركة التشادية للمياه. حيث تتواجد في حارتها معظم محطات ضنخ المياه، ففي حارة كليب مات توجد محطات ضنخ

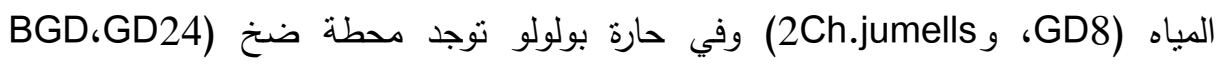

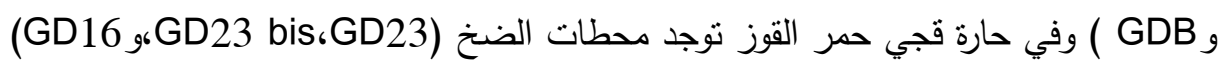
وتوجد محطة ضخ واحدة في حارة Gendarmerie وهي (GD1).فالدائرة الثانية لوحدها بها تسع محطات ضخ من بين ·. محطة ضخ للثركة في مختلف دوائر العاصمة أنجمينا.

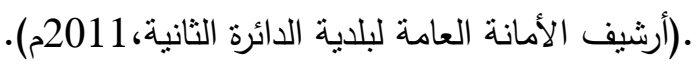

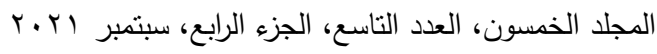

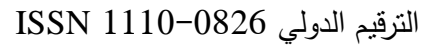

$$
\begin{aligned}
& \text { الترقيم الدولي الموحد الإلكتروني 3178-2636-26 التروب }
\end{aligned}
$$


مجلة العلوم البيئية

كلية الدراسات العليا والبحوث البيئية - جامعة عين شمس لئه

قمر محمد قمر وآخرون

\begin{tabular}{|c|c|c|}
\hline بلائة الائرة & المكان (الحارة) & $\begin{array}{l}\text { اسم البئر } \\
\text { GD1 }\end{array}$ \\
\hline الثانية & CEG1 & GD7 \\
\hline الثانيّة & Kleb - matt & GD8 \\
\hline الثانية & TIT de Goudji & GD16 \\
\hline الثانية & Goudji & GD23 \\
\hline الثانية & Goudji & GD23 bis \\
\hline الثانية & Centre STE & GD24 \\
\hline الثانبة & Béguinage ONDR & $B G D$ \\
\hline الثانية & Béguinage & GDB \\
\hline الثانية & Château rue 40 & 2 Ch. Jumells \\
\hline
\end{tabular}

اللون الأصفر يثير إلى المحطات الثلاثة التي أخذت منها العينات

التقسبي الادارى للائرة الثانبة على مستوى الحارات لعام20092

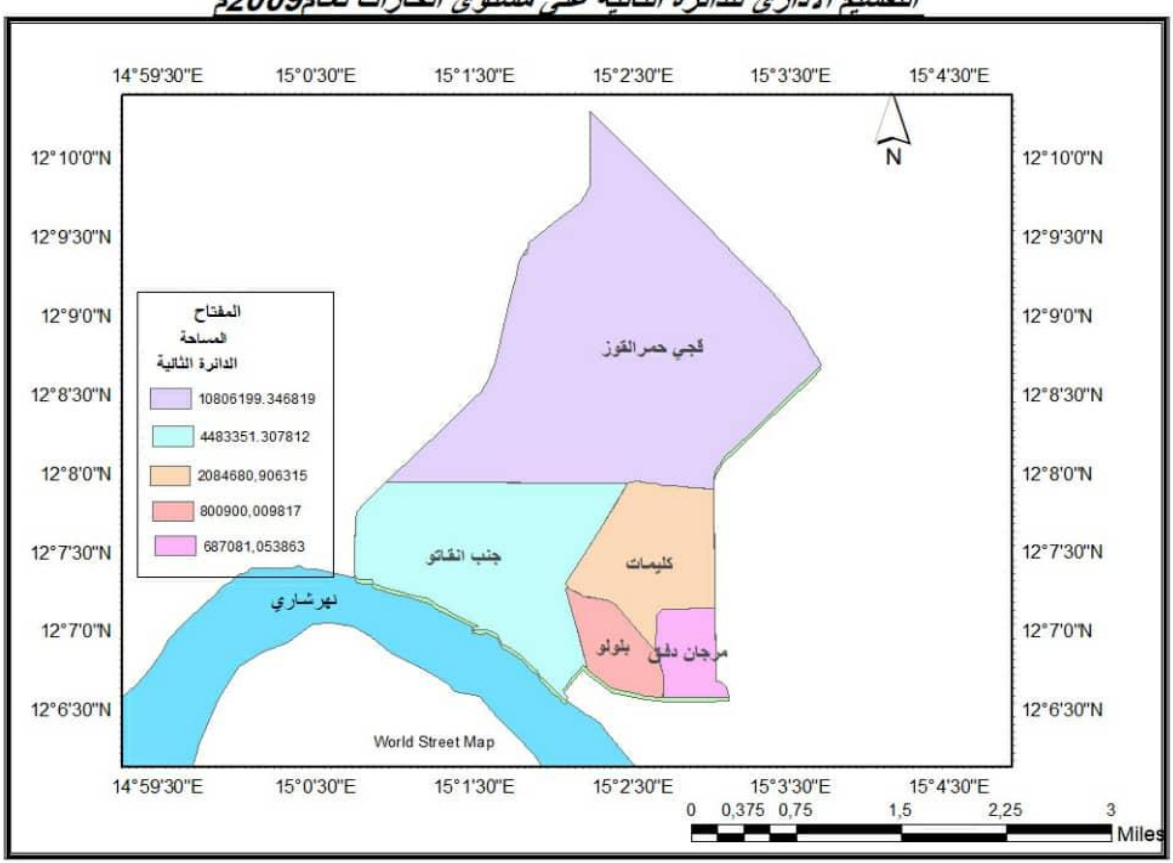

384

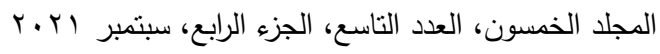

الترقيم الدولي 0826-1110 ISSN

الترقيم الدولي الموحد الإكتروني 3178-2636 


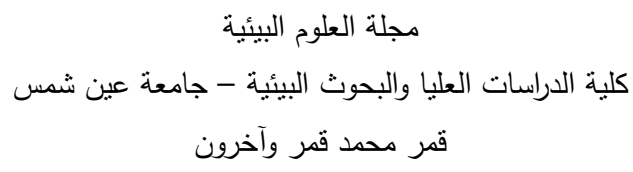

r ب جمع وتحليل عينات المياه Water sampling and analysis: r-r المواد Materials: جمعت عينات المياه من ثلاثة محطات الضخ للشركة النشادية للمياه [Kleb - matt) GD8،(CEG1)GD7)، (TIT de Goudji) GD16 ] كلها دمانه متواجدة ببلدية الدائرة الثانية. وتم الكثف عن نسب بعض المعادن الثقيلة (الكادميوم والنحاس) وبعض الايونات الذائبة (الكلور، النترات، النتريت) لهده العينات المأخوذة قبل المعالجة لهنبة

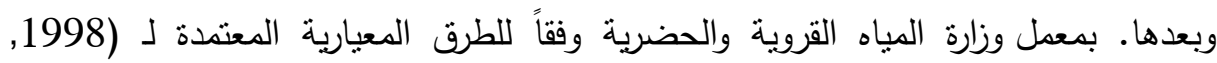
APHA أخذت العينات في أوعية بلاسنيكية نظيفة ومعقمة لمنع أي نشاط حيوي في عينات المياه.

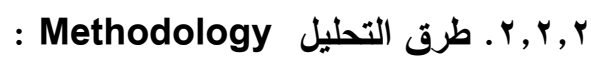


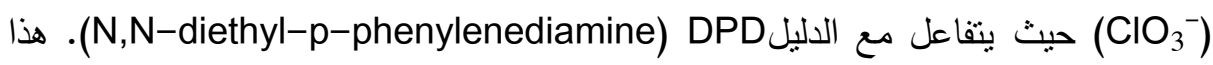
التفاعل يتتج لون وردي تتناسب قوته مع تركيز الكلور في العينة، حيث تتم قراءة نسبة الكلور

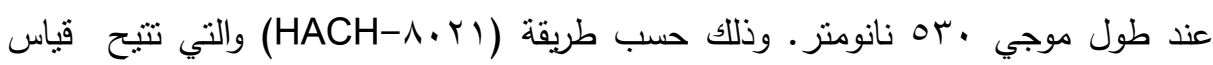

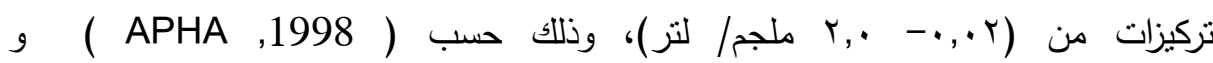

(WWW.dnr,2006)

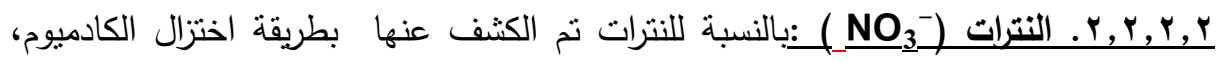

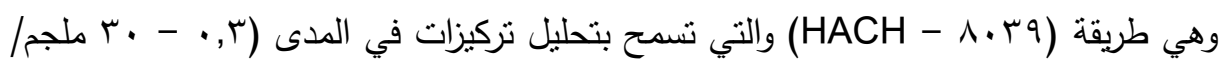

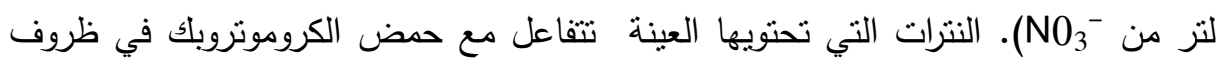

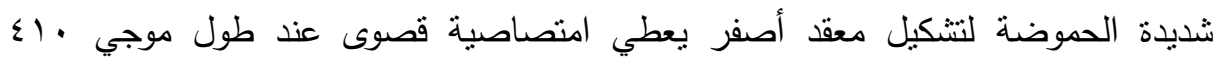

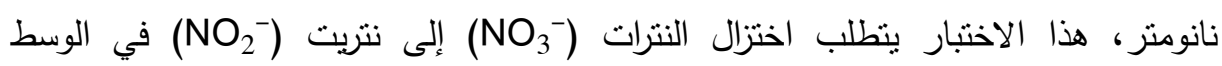
الحامضي، بواسطة مسحوق الكادميوم الذي يقوم بدور العامل المختزل للنترات. هذه الطريقة

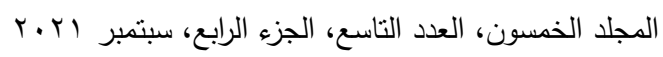

$$
\begin{aligned}
& \text { التزقيم الدولي 0826-0 الترني } \\
& \text { الترقيم الدولي الموحد الإلكتروني 3178-2636 }
\end{aligned}
$$


معتمدة من الوكالة حماية البيئة الأمريكية للطرق القياسية لإختبار مياه الثرب للسجل

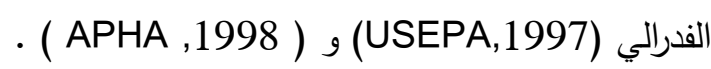

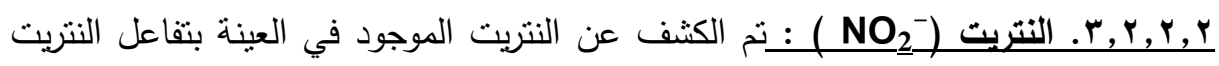
مع حمض الكبرتيك (Diazonium) (ليشكل مركباً وسطباً

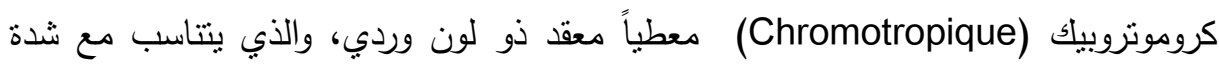

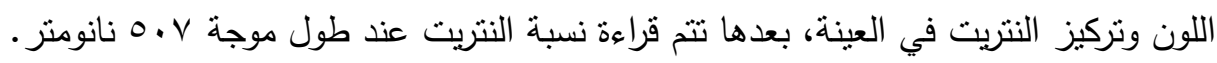

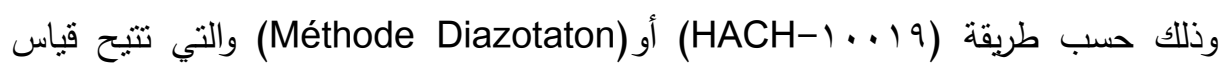

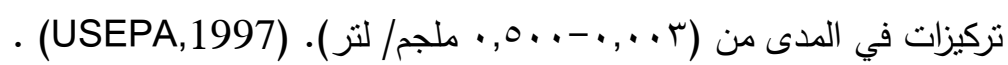

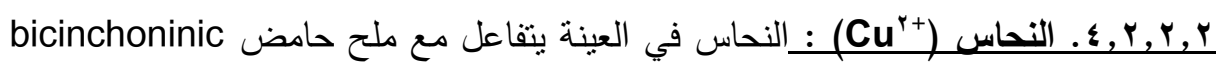
لكاشف النحاس CuVer1 أو CuVer2 حيث يتكون معقد ذو لون ارجواني، يتتاسب لونه مع تركيز النحاس. بعد ذلك تتم قراءة الإمتصاص للعينة عند طول موجي 560 نانومنز

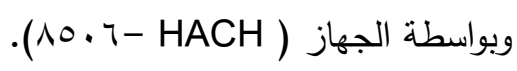

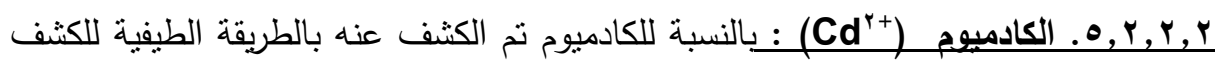
عن العناصر السامة في الأوساط المائية وذلك باستعمال جهاز قياس الكثافة الضوئية

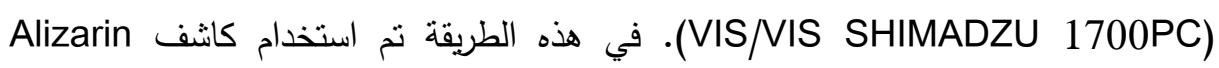

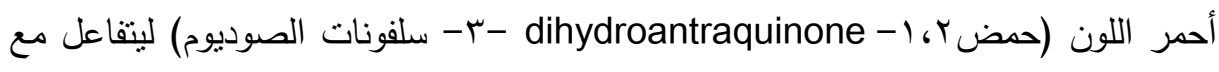
حامض الكبريتيك حيث ينتج الكادميوم والذي تتم قراءة نسبتة عند طول موجي r بـ نانومتر . ( APHA , 1998 )

\section{r. , Y, r}

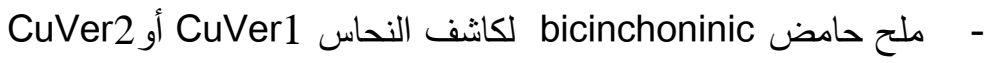

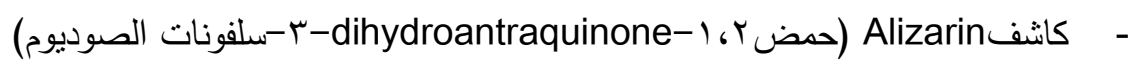

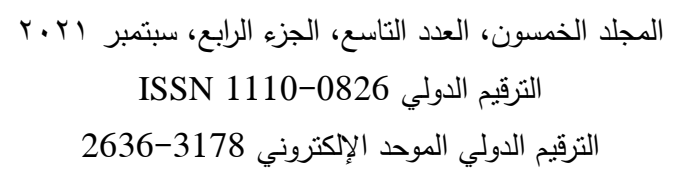




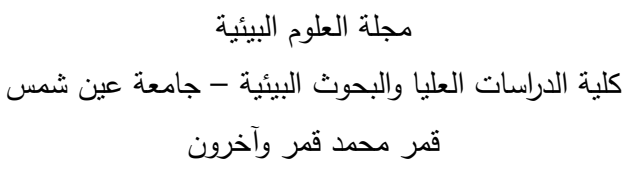

- مسحوق الكادميوم (العامل المختزل للنترات).

- مليل الكلور N,N-diethyl-p-phenylenediamine) DPD).

$$
\text { - - ممض الكبرتيك }\left(\mathrm{H}_{2} \mathrm{SO}_{4}\right)
$$

- أقراص ( لوحات قرصية: نبتريكول، كلوريد النحاس، كادميكول).

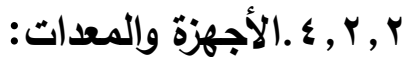

جهاز Spectrophotomètre (UV-VIS HACH DR/ 2400)، جهاز الطيف

Palintest House Kingsway. Tyre ) Photometre Palintest 5000 الضوئي (and Wear.NE110NS.U.K.

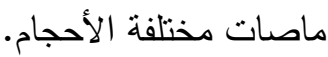
كل التجارب التي أجريت كررت ثلاثة مرات، ثم عبر عن كل نتيجة بالقيمة المتوسطة

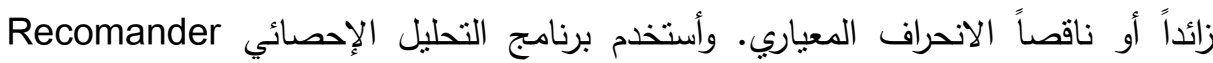
(R×643.2.5.Lnk)

\section{المتائج والمنالهشية}

جD7 (CEG1 جلول رقم (1) يوضح نتائج تحاليل العناصر المدروسة للمحطة لأولى

\begin{tabular}{|c|c|c|}
\hline العينات بعد المعالجة & العينات قبل المعالجة & العنصر \\
\hline $8.67 .10^{-1} \pm 6.66 .10^{-2}$ & $1.33 .10^{-1} \pm 4.16 .10^{-2}$ & $\mathrm{Cl}^{-}(\mathrm{mg} / \mathrm{l})$ \\
\hline $3.33 \mathrm{E}+01 \pm 2.52 \mathrm{E}+00$ & $4.17 \mathrm{E}++01 \pm 1.15 \mathrm{E}+00$ & $\mathrm{NO}^{3^{-}}(\mathrm{mg} / \mathrm{I})$ \\
\hline $8.33 .00 .10^{-2} \pm 1.15 . .10^{-2}$ & $1.87 .10^{-1} \pm 1.53 .10^{-2}$ & $\mathrm{NO}^{2-}(\mathrm{mg} / \mathrm{l})$ \\
\hline $1.33 .10^{-3} \pm 5.77 .10^{-4}$ & $6.33 .10^{-3} \pm 1.53 .10^{-3}$ & $\mathrm{Cd}^{+2}(\mathrm{mg} / \mathrm{l})$ \\
\hline $1.33 \mathrm{E}+00 \pm 1.53 .10^{-1}$ & $2.04 \pm 4.04 .10^{-2}$ & $\mathrm{Cu}^{+2}(\mathrm{mg} / \mathrm{l})$ \\
\hline
\end{tabular}

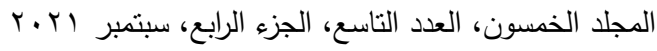

$$
\begin{aligned}
& \text { الترقيم الدولي 0826-08S 1110 } \\
& \text { الترقيم الدولي الموحد الإكتروني 3178-2636 }
\end{aligned}
$$


مجلة العلوم البيئية

كلية الدراسات العليا والبحوث البيئية - جامعة عين شمس لهن

قمر محمد قمر وآخرون

جلول (ץ): نتائج تحاليل العناصر المدروسة للمحطة الثانية Kleb - matt) GD8

\begin{tabular}{|c|c|c|}
\hline العينات بعد المعالجة & العينات قبل المعالجة & العنصر \\
\hline $9.47 .10^{-1} \pm 3.06 .10^{-2}$ & $1.47 .10^{-1} \pm 4.04 .10^{-2}$ & $\mathrm{Cl}^{-}(\mathrm{mg} / \mathrm{l})$ \\
\hline $3.47 \mathrm{E}+01 \pm 2.52 \mathrm{E}+00$ & $3.93 \mathrm{E}+01 \pm 5.77 .10^{-1}$ & $\mathrm{NO}^{3^{-}}(\mathrm{mg} / \mathrm{l})$ \\
\hline $7.33 .10^{-2} \pm 2.08 .10^{-2}$ & $2.10 \cdot 10^{-1} \pm 2.00 \cdot 10^{-2}$ & $\mathrm{NO}^{2-}(\mathrm{mg} / \mathrm{l})$ \\
\hline $3.00 .10^{-3} \pm 1.10^{-3}$ & $7.67 .10^{-3} \pm 5.77 .10^{-4}$ & $\mathrm{Cd}^{+2}(\mathrm{mg} / \mathrm{l})$ \\
\hline $1.63 \mathrm{E}+00 \pm 3.06 .10^{-1}$ & $2.12 \mathrm{E}+00 \pm 1.04 .10^{-\mathrm{T}}$ & $\mathrm{Cu}^{+2}(\mathrm{mg} / \mathrm{l})$ \\
\hline
\end{tabular}

جدول (ץ): نتائج تحاليل العناصر المدروسة المحطة الثالثة TIT-Goudji) GD16)

\begin{tabular}{|c|c|c|}
\hline العينات بعد المعالجة & العينات قبل المعالجة & العنصر | (العزي \\
\hline $9.47 .10^{-1} \pm 4.16 .10^{-2}$ & $1.50 .10^{-1} \pm 4.00 .10^{-2}$ & $\mathrm{Cl}^{-}(\mathrm{mg} / \mathrm{l})$ \\
\hline $3.13 \mathrm{E}+01 \pm 2.52 \mathrm{E}+00$ & $4.00 \mathrm{E}+01 \pm 2.00 \mathrm{E}+00$ & $\mathrm{NO}^{3-}(\mathrm{mg} / \mathrm{l})$ \\
\hline $1.13 .10^{-1} \pm 1.53 .10^{-2}$ & $2.07 .10^{-1} \pm 1.53 .10^{-2}$ & $\mathrm{NO}^{2-}(\mathrm{mg} / \mathrm{l})$ \\
\hline $3.67 .10^{-3} \pm 1.53 .10^{-3}$ & $8.67 .10^{-3} \pm 5.77 .10^{-4}$ & $\mathrm{Cd}^{+2}(\mathrm{mg} / \mathrm{l})$ \\
\hline $1.60 \mathrm{E}+00 \pm 2.65 .10^{-1}$ & $2.12 \mathrm{E}+00 \pm 6.81 .10^{-2}$ & $\mathrm{Cu}^{+2}(\mathrm{mg} / \mathrm{l})$ \\
\hline
\end{tabular}

جدول (ع ): يوضح مقارنة مستويات الثقة لنسب العناصر للمحطات الثناث قبل وبعد المعالجة

\begin{tabular}{|c|c|c|c|}
\hline$\overline{P \text { value }}$ & المحطات بعد المعالجة & المحطات قبل المعالجة & العنصر \\
\hline$\underset{6 * * *}{8.89 .10}$ & $\begin{array}{c}9.20 .10^{-1} \pm \\
4.62 .10^{-2}\end{array}$ & $1.43 .10^{-1} \pm 8,82 \cdot 10^{-3}$ & $\mathrm{Cl}^{-}(\mathrm{mg} / \mathrm{l})$ \\
\hline 0.00374 ** & $3.31 \mathrm{E}+01 \pm 1.68$ & $4.03 \mathrm{E}+01 \pm 1.20$ & $\begin{array}{l}\mathrm{NO}^{3-} \\
(\mathrm{mg} / \mathrm{l})\end{array}$ \\
\hline 0.00138 ** & $\begin{array}{c}9.00 .10^{-2} \pm \\
2.08 .10^{-2}\end{array}$ & $2.01 .10^{-1} \pm 1,26.10^{-2}$ & $\begin{array}{l}\mathrm{NO}^{2-} \\
(\mathrm{mg} / \mathrm{l})\end{array}$ \\
\hline $0.00725 * *$ & $\begin{array}{c}2.67 .10^{-3} \pm \\
1.20 .10^{-3}\end{array}$ & $7.5610^{-3} \pm 1.17 .10^{-4}$ & $\mathrm{Cd}^{+2}(\mathrm{mg} / \mathrm{l})$ \\
\hline 0.00434 ** & $\begin{array}{c}1.52 \mathrm{E}+01 \pm \\
1.64 .10^{-1}\end{array}$ & $2.09 \mathrm{E}+01 \pm 4.44 .10^{-2}$ & $\mathrm{Cu}^{+2}(\mathrm{mg} / \mathrm{l})$ \\
\hline
\end{tabular}


مجلة العلوم البيئية

كلية الدراسات العليا والبحوث البيئية - جامعة عين شمس ليه

قمر محمد قمر وآخرون
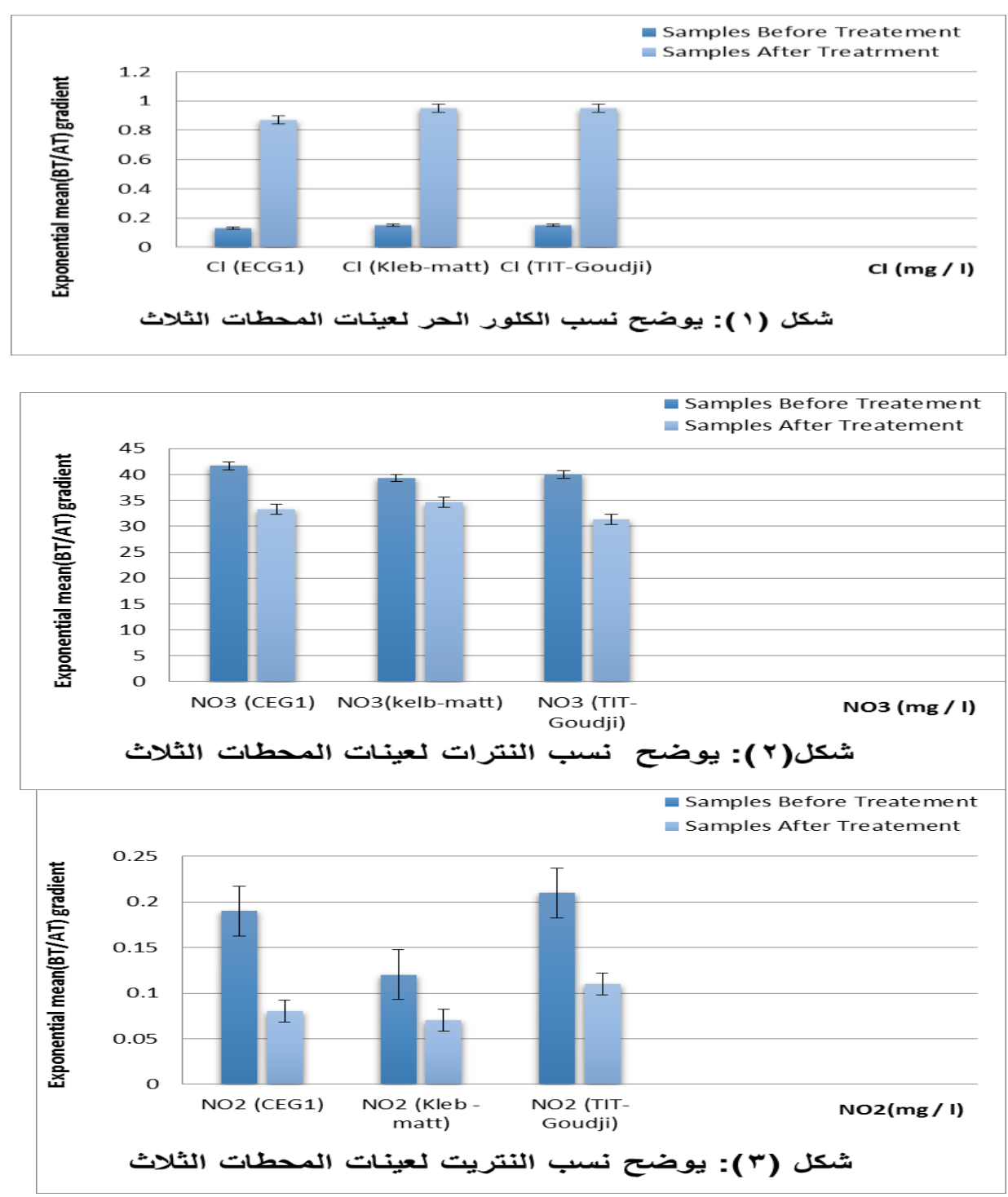

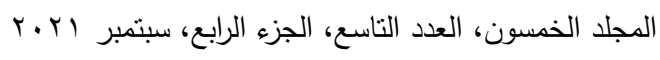

الترقيم الدولي 0826-0 1110 110

الترقيم الدولي الموحد الإكتروني 3178-2636 

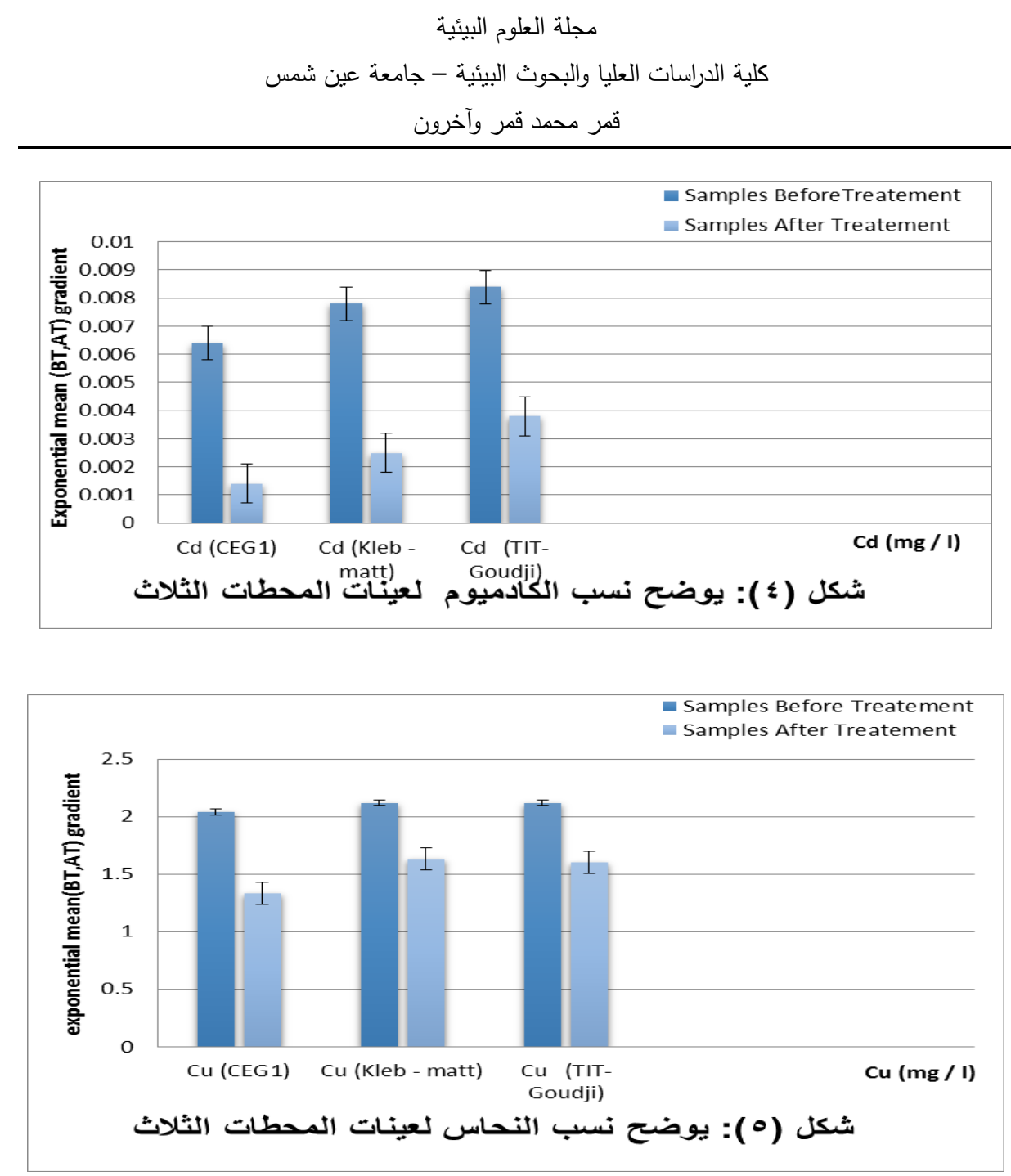

390

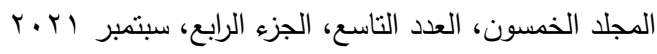

$$
\begin{aligned}
& \text { الترقيم الدولي 0826-1110 } \\
& \text { الترقيم الدولي الموحد الإكتروني 3178-2636 }
\end{aligned}
$$




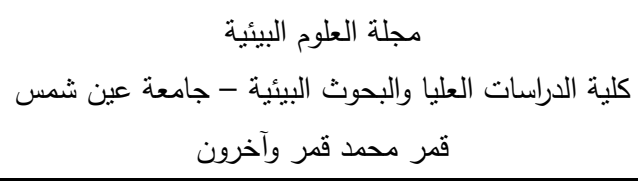

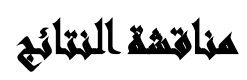

سجلت نتائج تحاليل الأيونات الذائبة والمعادن الثقبلة للعينات حسب الجدول (1) أعلاه للمحطات الثلاثة، وقورنت هذه النتائج بالمعايير القياسية للمنظمات والمؤسسات التالية: ، (CSHPF, 2006)، (APHA, 1998)، (EU,1992)، (WHO, 1993) (USEP,2005) و (USEPA,1997)

ا الكلور قبل المعالجة وبعد المعالجة للمحطات الثناث، فقراءات جميع العينات لنسب الكلور للعينات قبل المعالجة تزيد عن الحدود المسموح بها لـ (WHO,1993) للمياه الصالحة للثرب (0.2 - 0.5 ملجم/ لتز) فسجل أعلى متوسط للكلور في عينات المياه بعد

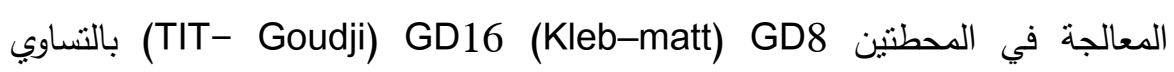

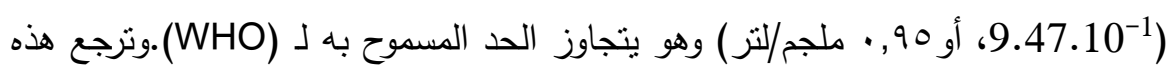

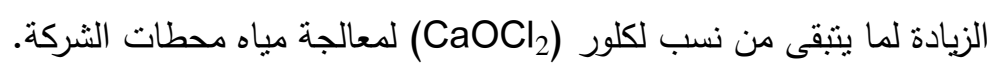
ومن الجدول (ء) أظهرت متوسطات عينات المياه للمحطات الثلاث قبل وبعد المعالجة

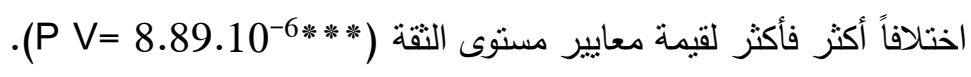

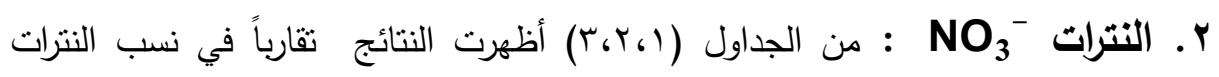
لعينات المياه قبل المعالجة فسجل أعلى متوسط للعينات قبل المعالجة في المحطة الأولى لـ

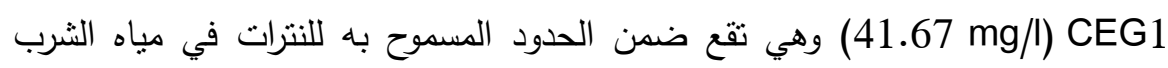
ومياه الصرف الصحي هو (ISmg) حسب (WHO). بينما يزيد عن حدود وكالة

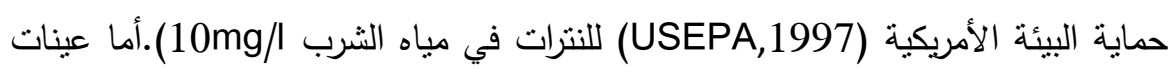
المياه بعد المعالجة فسجل أعلى منوسط للنترات في المحطة الثانية

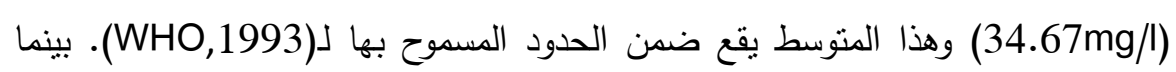

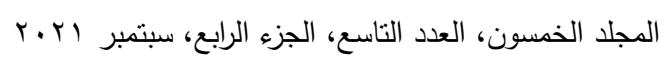

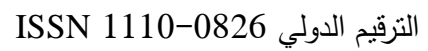

$$
\begin{aligned}
& \text { الترقيم الدولي الموحد الإلكتروني 3178-2636 }
\end{aligned}
$$


كان منتوسط المحطنين الأولى والثالثة (TIT-Goudji،CEG1) على الترتيب

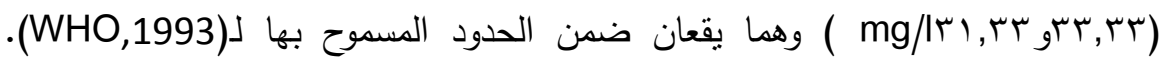
ويعزى سبب زيادة نسب النترات في عينات مياه الثرب غير المعالجة عن نسبتها في عينات المياه بعد المعالجة إلى نواجد مصدر المواد العضوية والمعدنية النيتروجينية في مياه الصرف الصحي لمصنع الخمور بالقرب من المحطة. كما أن هذه الزيادة قد ترتبط لئل

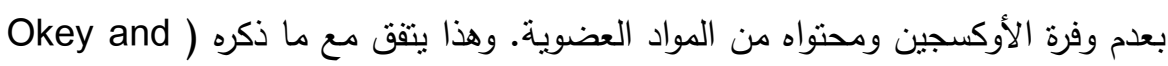

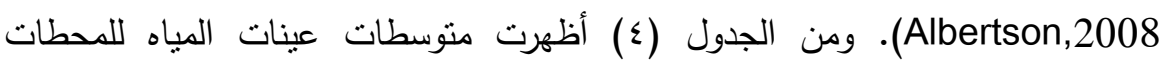
P V= ) الثلاث قبل وبعد المعالجة اختلافاً أكثر لقيمة معايير مستوى الثنة .$(0.00374 * *$ r. النتريت NO ${ }^{-}$: أظهرت نتائج نسبة النتريت في عينات مياه الشرب قبل المعالجة

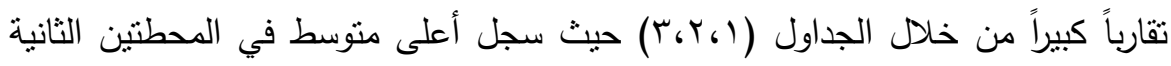

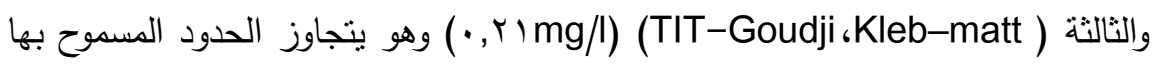
(0.0-0.10 mg/l) حسب وكالة حماية البيئة، وكذلك (WHO,1993). أما عينات المياه بعد المعالجة فسجل أعلى منوسط للنتريت في المحطة الثالثة TIT-Goudji 1.13.10-1 أوا/ 1.11 (0.11 ) وهذا المتوسط أيضاً يزيد عن الحدود المسموح بها ويعود سبب ارتفاع نسبة النتريت في نوعي عينات المياه إلى مصادر التلوث بالنتريت المنمثلة

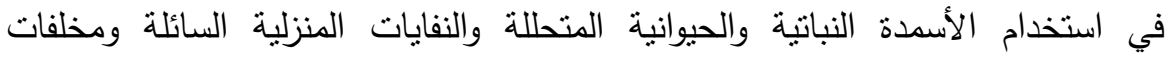

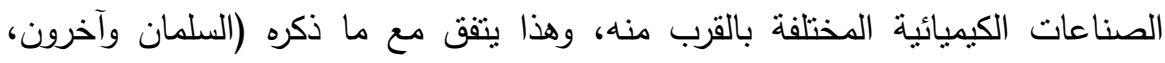

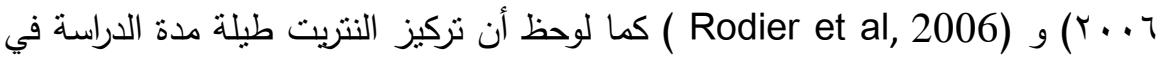
تغير وتباين مستمرين في محطات أخذ العينات. 
ومن الجدول (乏) أظهرت متوسطات عينات المياه للمحطات الثلاث قبل وبعد المعالجة اختلافاً أكثر لقيمة معايير مسنوى الثقة ( (P V V

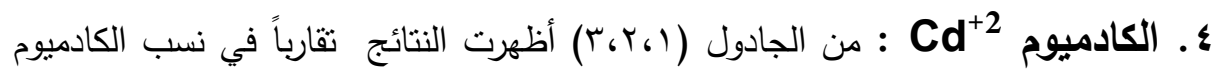
لعينات المياه قبل المعالجة فسجل أعلى متوسط للعينات قبل المعالجة في المحطة الثالثة

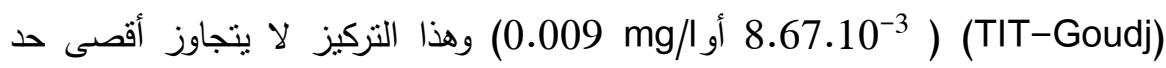

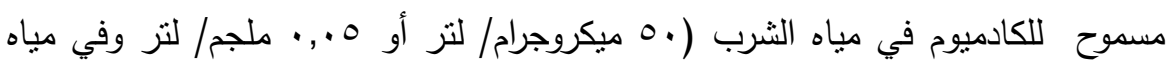

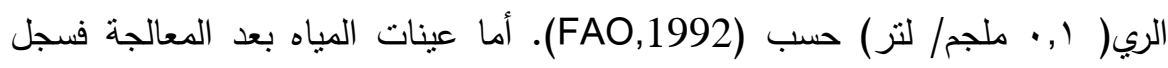

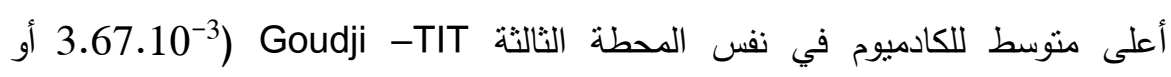
(0.0037 mg/l وهذا التركيز أيضا يقع ضمن الحدود المسموح بها للمعايير الدولية. ومن الجدول (ع) أظهرت متوسطات عينات المياه للمحطات الثلاث قبل وبعد المعالجة اختلافاً المعالجة اختلافاً أكثر لقيمة معايير مستوى الثقة ( ه. النحاس Cu

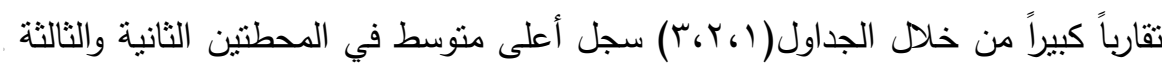
(2.12mg/l) (TIT-Goudji ،Kleb-matt لنسبة النحاس في مياه الثرب ( . . . ميكروجرام/ لتز أي r ملجم/ لتز ) بينما يتجاوز

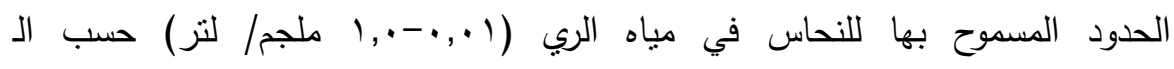

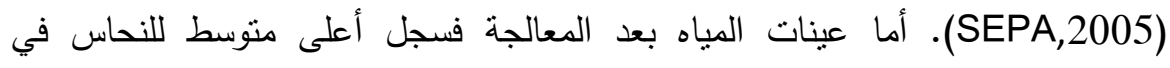
المحطة الثانية Kleb-matt (1.63 mg/l وهدا التركيز لا يتجاوز أقصى حد مسموح به للنحاس في مياه الثرب ومياه الري. ويرجع السبب في ارتفاع نسبة النحاس في عينات المياه غير المعالجة في هذه المحطنين الثانية والثالثة نتيجة لتآكل الأنابيب النحاسية التي في في التياه تستخدم في شبكات توزيع المياه لهذه المحطة. وأن زيادة نسبة النحاس وفي جسم الإنسان

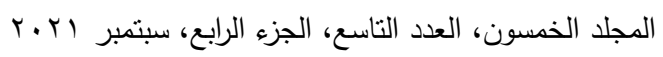

$$
\begin{aligned}
& \text { الترقيم الدولي 0826-1110 } \\
& \text { الترقيم الدولي الموحد الإلكتروني 3178-2636 }
\end{aligned}
$$


Verma ( تسبب ارتفاع نسبة البولينا، وارتفاع ضغط الدم، وفقدان الوعي، والحمى الطارئة

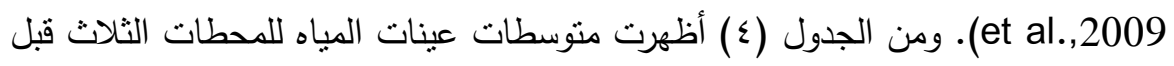

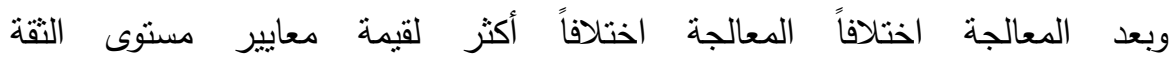

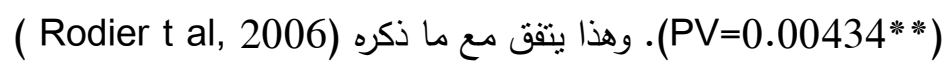

\section{CONCLUSION الاستمنيماتج}

يستتج أن عينات المياه قبل وبعد المعالجة لمحطات الضخ الثلاثة [CEG1) GD7)، [ (TIT de Goudji) GD16، أعطت تبايناً أكثر فأكثر لقيمة معايير (Kleb-matt)GD8

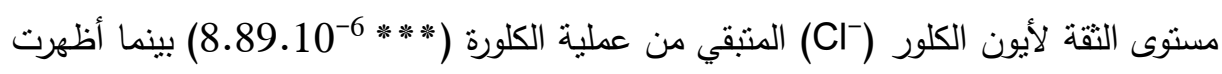
(النترات 0.00374***) للمحطات الثلات قبل وبعد المعالجة اختلافاً المعالجة اختلافاً أكثرً لقيمة معايير مستوى الثقة. ولوحظ أن قراءات العينات قبل المعالجة للعناصر الددروسة تزيد عن قراءات عينات لعناصر

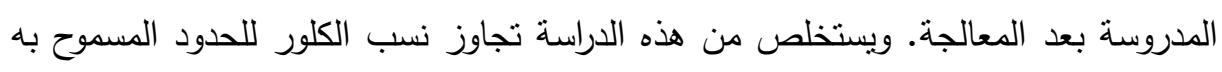

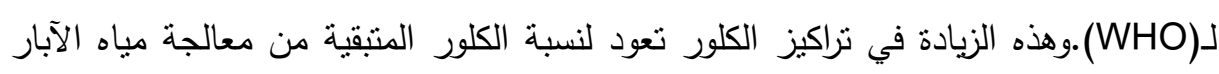

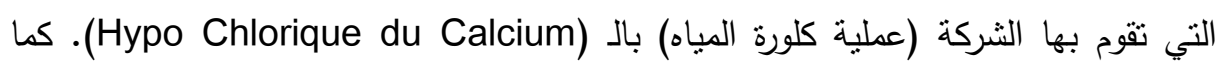

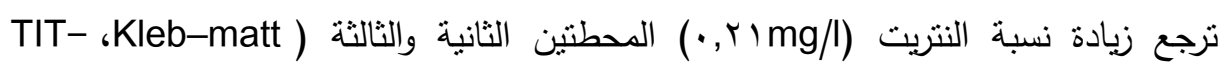
Goudji والنفايات المنزلية السائلة ومخلفات الصناعات الكيميائية المختلفة بالقرب منه. أما بالنسبة الصنية

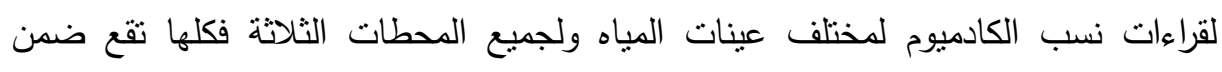
المعايير والحدود المسموح بها. بينما أوضحت نتائج نسب النحاس في عينات مياه الثرب

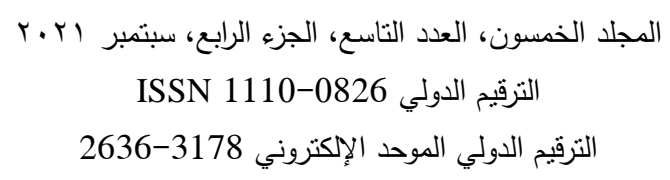


ارتفاعاً في المحطنين الثانية والثالثة ( Kleb-matt، (2.12mg) وهذا التركيز يتجاوز أقصى حد مسموح به لنسبة النحاس في مياه الثرب ومياه الري. ويرجع السبب في ارتفاع نسبة النحاس في عينات المياه غير المعالجة في هذه المحطنين الثانية والثالثة نتيجة لتآكل الأنابيب النحاسية التي تنتخدم في شبكات توزيع المياه لهذه المحطة. أما عينات

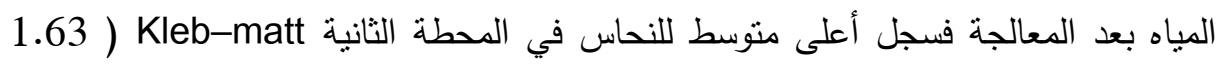
وهدا التركيز لا يتجاوز أقصى حد مسموح به للنحاس في مياه الثرب ومياه الري.

\section{Recommendations اللموسياهت}

توصي الورقة العلمية بالتوصيات النالية:

1-تخفيض نركيز معاملة المياه بالكلور (هيبو كلوريد الكالسيوم) في المحطات التي تزيد فيها

$$
\text { نسبة الكلور عن الحدود المسموح بها للكلور في مياه الثرب. }
$$

r-استبعاد مصادر النتريث المتواجدة بالقرب من المحطتين الثانية والثالثة بهدف تقليل نسبة

$$
\text { تلوث مياهها. }
$$

r-ضرورة معالجة مياه محطات الضخ للشركة التشادية للمياه بتقنية المعالجة بالأوزون تفادياً

للمخاطر الصحية التي تتتج من تلوث هذه المياه ببعض العناصر الكيميائية السامة.

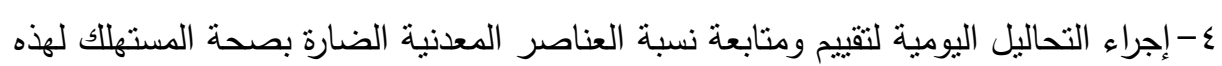

$$
\text { ه- استخدام التكنولوجيا الحديثة المستخدمة في مجال معالجة وتتقية المياه. }
$$

1-ضرورة إجراء الصيانة الثهرية أو الدورية لمختلف محطات الثركة التشادية للمياه

بالعاصمة والولايات.

V-تزويد المواطنين بمطهرات ومعقمات لمياه الثركة تفادياً للعديد من المخاطر الصحية.

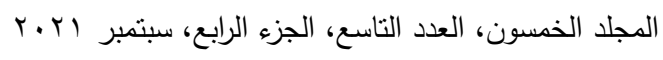

$$
\begin{aligned}
& \text { التزقيم الدولي 0826- ISSN 1110 } \\
& \text { الترقيم الدولي الموحد الإلكتروني 3178-2636 }
\end{aligned}
$$




\section{مجلة العلوم البيئية \\ كلية الدراسات العليا والبحوث البيئة - جامعة عين شمس \\ قمر محمد قمر وآخرون}

^-ضرورة إصلاح وصيانة شبكات توزيع مياه الثركة النتادية نتيجة لمرور فترة زمنية طويلة لانثاءها.

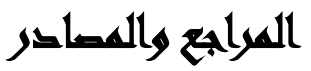

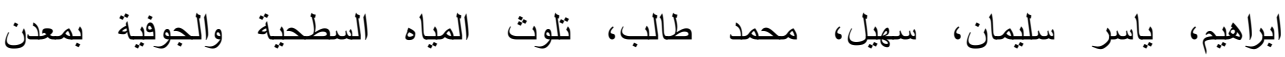

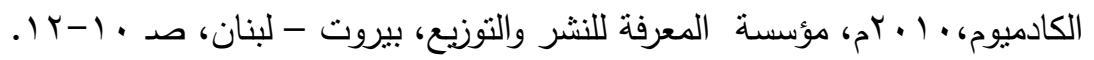

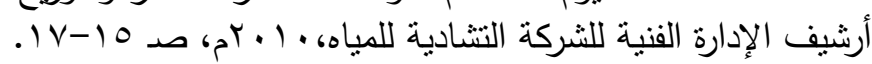

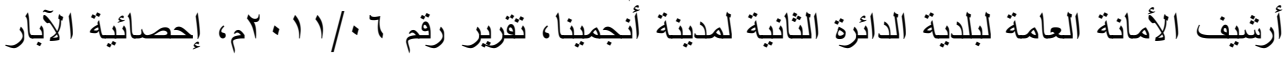

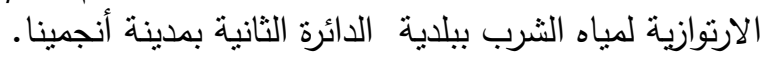

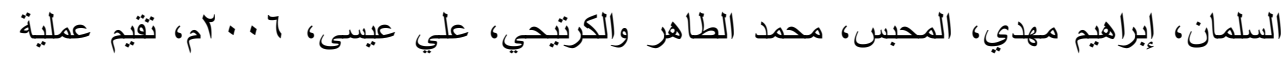

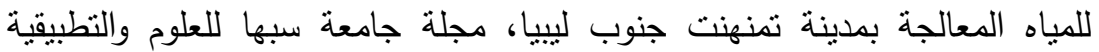

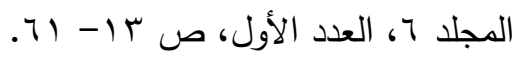

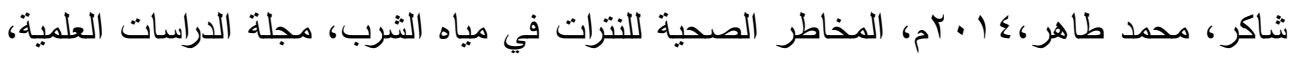

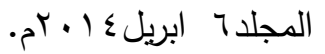

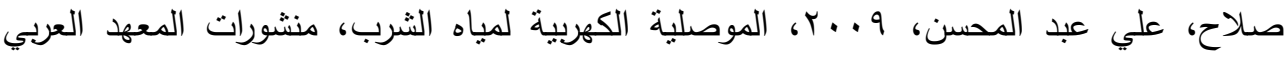

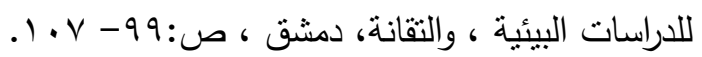

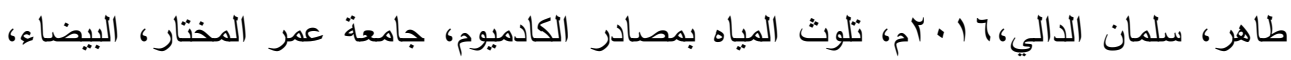

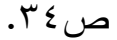

عابد، مصطفى رشاد، با • rم، إعادة استخدام المياه الملوثة بالمعادن التقبلة، ،مجلة الأبحاث

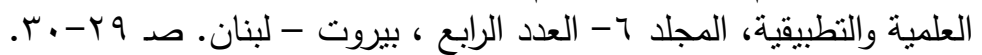

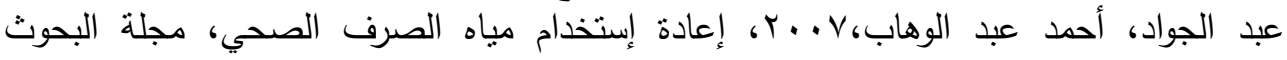

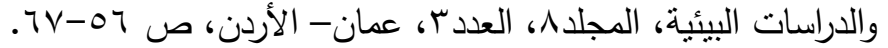

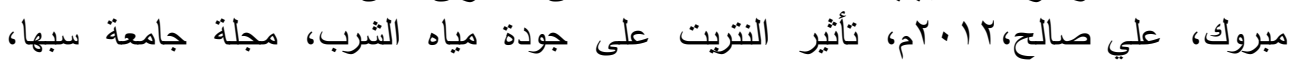

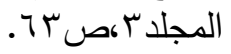

مجدي ياسر فخري، 10 • بم، معالجة بقايا المعادن الثقيلة في مياه الثرب لبعض مستشفيات مدينة

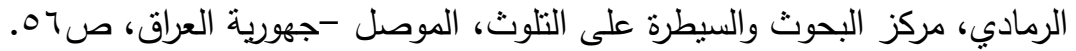

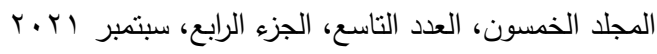

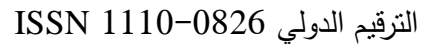

$$
\begin{aligned}
& \text { الترقيم الدولي الموحد الإلكتروني 3178-2636 }
\end{aligned}
$$




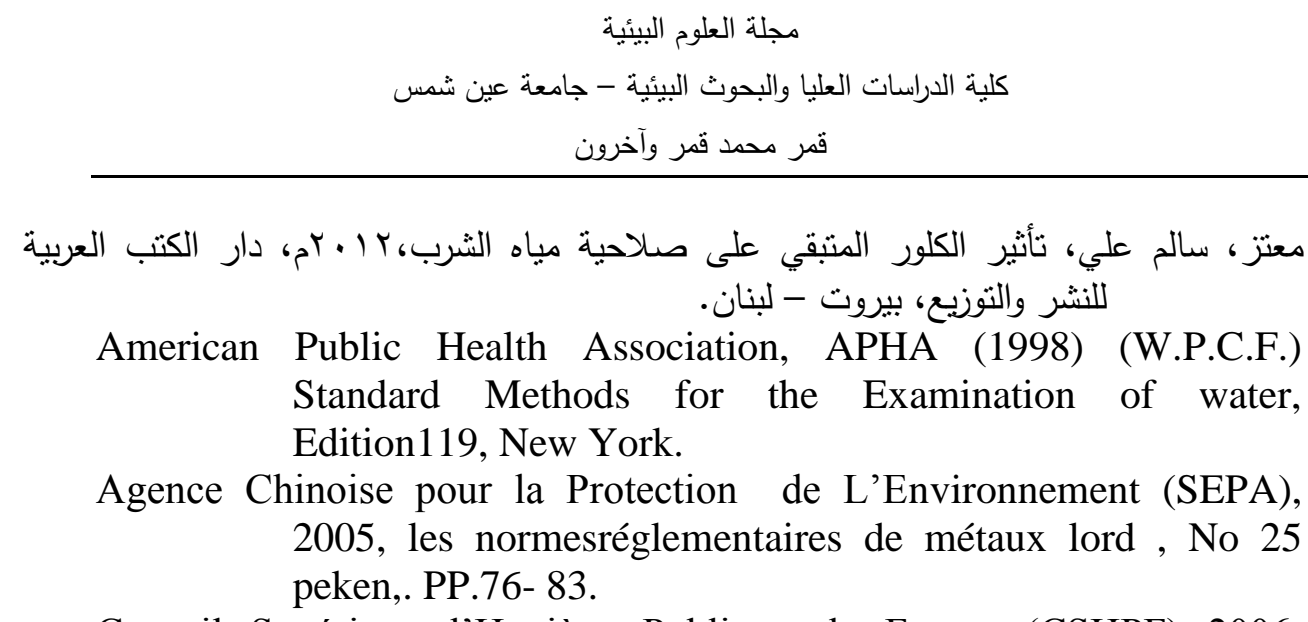

Conseil Supérieur d'Hygiène Publique de France (CSHPF) 2006, Guidelines for Heavy metal ions in Drinking Water, paris Univ. France. PP. 43- 48.

European Union (EU), 201 ${ }^{\Upsilon}$ Guidelines for Quality drinking water. PP. 14.

Food and Agriculture Organisation, (FAO ) 1992. Wastewater treatment and use in agriculture.Technial papers $\mathrm{N}^{\circ} 47$, Roma Italy. PP. 143- 146.

United Stats Environmental Protection Agency (USEPA), 1997, Guidelines for Drinking water and Wastewater used in irrigation, Volume7. PP. 19.

Okey, R. W. and O. E. Albertson. 2008. The role of the diffusion in regulating rate and Masking temperature effects on fixed film nitrification 61: PP. 170- 176.

Rodier S.A. and jean B. Cloud. 2006. "Effuent from own waste water treatment: New possibilities foe use": Deutsch Milchwirtscaft, 50:12, PP. 496.

World Health Organisation (WHO), 1993. Guidelines for Drinking Water Quality, Volume1: Recommendations WHO, Geneva 1993.

Department of Natural Science. (WWW.dnr,2006) Wastewater characterization for evaluation of biological phosphorus removal.

Available

$$
\begin{aligned}
& \text { المجلد الخمسون، العدد التاسع، الجزء الرابع، سبتمبر اY r. } \\
& \text { الترقيم الدولي 0826-1110 118SN } \\
& \text { الترقيم الدولي الموحد الإكتروني 3178-2636 }
\end{aligned}
$$




$$
\begin{aligned}
& \text { مجلة العلوم البيئية - مائة } \\
& \text { كلية الدراسات العليا والبحوث البيئية - جامعة عين شمس لئس } \\
& \text { قمر محمد قمر وآخرون }
\end{aligned}
$$

www.dnr.state.wi.us/org/water/wm/water/wm/www/biopho s//into.htm.

Verma,P.S.and Agarwal, V.K. 2009. Principles of Ecology, TRFQ international Programme of Health, Michigan.

\title{
STUDY OF SOME HEAVY METALS AND \\ DISSOLVED IONS OF DRINKING WATER IN MUNICIPALITY OF THE SECOND DISTRICT OF N'DJAMENA
}

\section{Gamar M. Gamar ${ }^{(1)}$ and Mohagir A. Mohager ${ }^{(2)}$}

1) Department of Life and Earth sciences, Higher Teachers' Training School of N'Djamena. P.BOX: 460. N'Djamena - Chad. 2) Department of Chemistry, College of Pure and Applied Sciences, University of N'Djamena, P.BOX: 1027, N'Djamena -Chad.

\begin{abstract}
Water samples were collected before treatment (directly from the artesian well) the Chadian Water Company (STE): [GD7, GD8. GD16]. The some Heavy metals and Dissolved ions of these samples were determined in the laboratory of the Ministry of Rural and Urban Waters, according to the approved standard methods. The results of the analyzes for various properties were compared with the permissible values and limits of the WHO, EU, and some health and environmental bodies and institutions .the reading of the samples before treatment for the studied elements are the more than in the samples after treatment. The Water samples before and after treatment for the sites gave a very 398

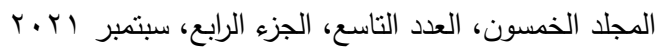

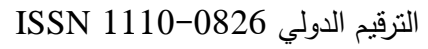

$$
\begin{aligned}
& \text { الترقيم الدولي الموحد الإلكتروني 3178-2636 }
\end{aligned}
$$




$$
\begin{aligned}
& \text { مجلة العلوم البيئية } \\
& \text { كلية الدراسات العليا والبحوث البيئية - جامعة عين شمس } \\
& \text { قمر محمد قمر وآخرون }
\end{aligned}
$$

large variation in the confidence level of residual chlorine ion $\left(8.89 .10^{-6}\right.$ $* * *)$ Wihle I showed $\left(\mathrm{NO}_{3}{ }^{-} \cdot \mathrm{NO}_{2}{ }^{-} \cdot \mathrm{Cd}^{+2} \cdot \mathrm{Cu}^{+2}\right)$ respectively $(0.00374 * *$ ، $\left.0.00138 * * *_{0} 0.00725 * * *_{0} 0.00434 * *\right)$ the two sites (GD8 and GD16) recorded heights average chlorine $(0.95 \mathrm{mg} / \mathrm{l})$ it exceeds the permissible limit of WHO. As for nitrate the average of the samples before treatment for $(41.67 \mathrm{mg} / \mathrm{l})$ it exceeds the limit of the USEPA for nitrate in drinking water $(10 \mathrm{mg} / \mathrm{l})$. the Water samples before and after treatment for the three sites of Cadmium ratios it was all within permissible limits. The heights mean of Copper was recorded in the drinking water samples before treatment in the two sites (GD7 and GD8) $(2.12 \mathrm{mg} / \mathrm{l})$ it exceeds the permissible limits of the SEPA (0.01 $-1.00 \mathrm{mg} / \mathrm{l})$.

Keywords: Dissolved ions, Chlorine Nitrate, Nitrite, Copper, Cadmium, Ndjamena.

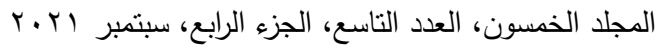

$$
\begin{aligned}
& \text { الترقيم الدولي 0826-0 1110 } \\
& \text { الترقيم الدولي الموحد الإلكتروني 3178-2636 }
\end{aligned}
$$

